\title{
Establishing Multicultural-Oriented Teacher Education System: An Empirical Research on Cultural Conflicts between Teachers and Students in Tibet
}

\author{
Guoping Zheng \\ Key Research Institute of Humanities and Social Sciences at University, Center for Studies of Education and \\ Psychology of Ethnic Minorities in Southwest China, Southwest University, Chongqing, China \\ Email: scayzgp815@163.com
}

Received 10 April 2014; revised 16 May 2014; accepted 23 May 2014

Copyright (C) 2014 by author and Scientific Research Publishing Inc. This work is licensed under the Creative Commons Attribution International License (CC BY). http://creativecommons.org/licenses/by/4.0/

(c) (i) Open Access

\section{Abstract}

This study aimed at gaining an in-depth knowledge of cultural conflicts between Han and Tibetan teachers, between teachers and students in Tibetan Autonomous Region, then discussed and analyzed the reasons for that, and finally attempted to solve the issue by establishing culture-oriented teacher education system. This study chose Dazi Junior Middle School as the case empirical study. Data for this study were gathered through interviews, participant observations, questionnaire surveys and document analysis, to analyze the cultural conflicts and its reasons. Findings suggest that teachers are "professionals" as well as "cultural workers", also teacher cultural buildings and works. The mission of teacher education is to preserve and establish the ecology of the cultural development of teachers to promote teacher's self-development in the interaction of self-being and self-making culture. Therefore, Teacher education system based on multi culture in ethnic minority regions should be established to realize multi-cultural harmonious symbiosis.

\section{Keywords}

Teacher Education, Multiculture, Cultural Conflicts, Harmonious Symbiosis, Case Study

\section{Introduction}

Tibet is one of the minority autonomous regions in the southwest border in China. There are the main Tibetansand other 44 ethnic minorities, including Menba, Luba, Hui, Naxi minorities and so on. In addition, Tibet is al- 
so an autonomous region where there coexist multi-religions, including Tibetan Buddhism, Islam and Catholicism. This multi-ethnic, multi-religious harmony has formed its particular multi culture. Culture is the whole meaning of people living and indispensable to everyone in life [1]. It is the culture to bring people together, namely ideas and principles they shared [2]. Culture isn't designed according to the rationality, but long and complex historical product, so every culture contains contradiction and invalidity [3]. As the main form of transmission and continuation of culture and an integral part of social and cultural process, education "inherits culture to be coherent history and to become the starting point of creating a new culture for everyone [4]". The task of inheriting and carrying forward the traditional multi culture in Tibet naturally falls onto Tibet's education. The educators of Tibet's education play its important role as a bridge. "Han Teachers to Tibet" is one of the national education policies. The Han teachers, who are in other culture environment, and Tibetan teachers and students with the Tibetan cultural characteristics constitute a multi-cultural field, which also brings the multicultural conflicts. Some researchers believe that cultural conflict refers to the different cultures and subcultures under the same cultural system repel each other and deny each other [5]. According to the analysis of existing research results, there are three main kinds of common way of thinking to study the conflicts between teachers and students, which are: first is the analysis of the pedagogy; second is the psychological analysis; third is the sociological analysis [6].

According to the data, the scholar who studied multicultural education the earliest in China was Zongmei Shen in 1992 in the paper of "the Challenge to American Mainstream Culture". For the first time, he translated "multi culturalism" into Chinese. But due to various constraints, the research on multicultural education system was also slightly thin. Entering the 21st century, the research on multicultural education became more and more. In 2003, Yule Jin put forward "strengthening the study of the multicultural curriculum" [7]. In 2004, Jinzhou Zheng in the book "Multicultural Education" studied the meaning and goal of multi-cultural education, multicultural curriculum, teaching, and teachers and students in multicultural education [8]. In 2006, from the perspective of comparative study, Minggang Wan explored the history method and object of multicultural education comparison research, the concept debate of multicultural education, multicultural education and its critique in western countries, the history of China's ethnic minority education policies, etc., as well as the study of teacher training under the background of multicultural education [9].

Therefore, the purpose of this study is to solve the cultural conflicts between Han and Tibetan teachers by exploring to build culture-oriented teacher education system, attempting to weaken the negative effects of cultural conflicts and highlighting the active role of cultural conflicts to develop self in the cultural interaction, so as to achieve multi-cultural harmony.

\section{Research Methodology}

\subsection{Research Design}

This study attempted to fill a perceived gap in the literature on teacher education and solved cultural conflicts between Han and Tibetan teachers, between teachers and students in Tibetan Autonomous Region by exploring to build culture-oriented teacher education system. Because of the nature of the questions the study sought to answer, the case study method was employed. Data collection was guided by the following research questions:

1) What are the cultural conflicts between Han and Tibetan teachers, between teachers and students in Tibet?

2) What are the reasons for the cultural conflicts between them?

3) How should culture-oriented teacher education system be established?

\subsection{Research Sample and Data Collection}

Dazi County is $25.5 \mathrm{~km}$ to Lhasa and locates in south-central area in Tibet Autonomous Region, the midstream of Lhasa River. It is a relatively developed region in Tibet. This study chose Dazi Junior Middle School as the case study. Data for this study were gathered through (a) interviews with the teachers and students, (b) participant observations of activities of teachers and students, (c) questionnaire surveys and (d) document analysis, to analyze the cultural conflicts and its reasons. All those statistical data came from Tibet Statistical Yearbook (2013) and fieldwork. The use of fieldwork methods could increase the persuasive argument and draw reliable conclusions. 


\section{Research Findings}

The particularity of Tibetan history, situation of modern education, economic status, and plateau region restricted the development of the local teacher education. Therefore, "Han Teachers to Tibet" became one of our national education policies. But the non-Tibetan teachers from non-Tibetan regions who were mainly Han nationality paid no enough attention to the particularity of minority education due to the lack of understanding and awareness of multi-ethnic traditional culture, which led to the multi-cultural conflicts in the multicultural educational environment.

\subsection{Ratio Imbalance of Ethnic Teacher-Student Number}

It was necessary to get a good understanding whether the ratio of teacher-student number of the Han and Tibetan nationalities was at a reasonable structure.

First, from the aspect of teachers' structure in Tibet (Tibet Statistical Yearbook, 2013) (see Table 1), the proportion of elementary, junior and senior high school minority teachers were respectively 90.34\%, 58.29\% and $58.13 \%$. It could be seen that elementary and secondary school teachers were mainly ethnic minority ones. But as one minority area, the proportion of minority teachers was still low.

Secondly, from the aspect of teachers' structure in Dazi Junior School (Tibet Statistical Yearbook, 2013) (see Table 2), the proportion of Tibetan teachers was 73.91\%, while the proportion of Tibetan students was $97.38 \%$. Although the ratio of Tibetan teachers was higher than the average ratio of the same secondary schools, compared to the students' ethnic structure in the school, it's evident that the proportion of Tibetan teachers was still at a low level, ethnic teacher-student number ratio was still in the state of imbalance.

\subsection{Poor Quality of Han and Tibetan Teachers, Poor Quality of Bilingual Teaching}

In people's opinion, the education degree of all teachers in minority areas should be low. However, for some more developed regions in minority areas, through such ways as policy support and teachers' re-education, the education degree of full-time teachers was the same or even slightly higher than that in some inland rural county schools. Data from Table 3 showed that the education degrees of full-time teachers in Dazi Junior School reached the policy substandard. Han teachers generally had higher education backgrounds, five of whom received postgraduate degree. But the interviews indicated that the education degree didn't mean the quality of teachers. Although Tibetan teacher qualifications reached the basic standard, it's still difficult to guarantee the quality of teachers due to the lower threshold of college entrance examination in Tibet.

Table 1. Ethnic structure ofteachers in Tibet autonomous region.

\begin{tabular}{ccccccc}
\hline & \multicolumn{2}{c}{ Elementary School } & \multicolumn{2}{c}{ Junior School } & \multicolumn{2}{c}{ Senior High School } \\
\hline & Number & Percentage & Number & Percentage & Number & Percentage \\
Minorities & 11768 & 90.34 & 2899 & 58.29 & 865 \\
Han & 1258 & 9.66 & 2074 & 41.71 & 623 & 41.87 \\
Total & 13026 & 100 & 4973 & 100 & 1488 \\
\hline
\end{tabular}

Table 2. Ethnic structure of teachers and student in Dazi junior school.

\begin{tabular}{cccccccc}
\hline & \multicolumn{2}{c}{ Number of full-time teachers } & \multicolumn{3}{c}{ Number of students } \\
\hline Nationalities & Tibetan & Han & Others & Tibetan & Han & Others \\
Dazi Junior School & 85 & 30 & 0 & 1302 & 25 \\
\hline
\end{tabular}

Table 3. Education degree of full-time teachersin Dazi junior school.

\begin{tabular}{|c|c|c|c|c|c|c|c|c|}
\hline \multirow{3}{*}{$\begin{array}{c}\text { Nationalities } \\
\text { Education Degree }\end{array}$} & \multicolumn{8}{|c|}{ Education Degree of Full-Time Teachers } \\
\hline & \multicolumn{4}{|c|}{ Tibetan } & \multicolumn{4}{|c|}{ Han } \\
\hline & Postgraduate & Bachelor & College & High School & Postgraduate & Bachelor & College & High School \\
\hline Dazi School & 1 & 75 & 9 & 0 & 4 & 26 & 0 & 0 \\
\hline
\end{tabular}


Therefore, the issue of the teachers' quality wasn't on the education levels, but was mainly attributed to the overall quality of the teachers, especially low bilingual teaching ability. All the Tibetan teachers could speak Chinese, but the Chinese level wasn't high. While Han teachers were at a low level of Tibetan language, and unable to communicate with others in Tibetan language.

Language is the most important communication and thinking tool of mankind, the important carrier of information exchange, the deep lens of ethnic culture and the second face of the nation. It's surveyed that all the textbooks of secondary schools were compiled in the Chinese language, except Tibetan language course. In the use of the language of instruction, the Tibetan teachers generally taught in both Tibetan and Chinese language, while the Han teachers only taught in the Chinese language. The reason was that Han teachers hardly lived and studied here, which led to their no understanding of Tibetan language and culture. Only one Han teacher who ever lived and studied here could speak Tibetan and Chinese in Dazi Junior School.

Language was a communication tool and also the messenger to convey feelings. If language caused an obstacle in the understanding and exchange in the students' study and life, on the one hand, it would have an impact of students' love and trust to teachers, causing teaching difficulties; on the other hand, it would affect students' interest and enthusiasm in the course, resulting in academic difficulties. When they were in the survey asked "Do you prefer Tibetan or Han teachers, and why?" most of students thought they preferred the Tibetan teachers. The reason was that Tibetan teachers in the class could explain something in Tibetan language to be better understood, while Han teachers couldn't do that, and even some Han teachers' Mandarin with the dialect was hard to be understood.

\subsection{Deep Cultural Barriers and Less Cultural Communication between Teachers and Students, between Teachers and Teachers of Different Nationalities}

Here cultural communication should be exactly called cross-cultural communication. It meant that it's a cultural phenomenon of ordinary communication in which people with different cultural backgrounds engage in communication. It widely existed in the communicative activities between different countries and regions, different ethnic groups, different culture classes, different occupations and even individuals. The issues mainly involved the aspects such as policies, political views, values, ethnic customs and manners, thereby enabling the crosscultural study to focus on the research on mainstream cultural characteristics of a country or region, which were further subdivided into mainstream culture, sub-culture, regional culture and even small-group culture [10]. Therefore, here cultural communication meant the cultural communication between Han and Tibetan nationalities.

However, in the interview it's found that cultural barriers between teachers and students, between teachers and teachers of different nationalities were deep and their cultural communication was less. As they were lack of understanding of Tibetan traditional culture, Han teachers didn't teach from the particularity of ethnic education. In the interview with the students, Tibetan students said that Han teachers hardly introduced the Han culture in or out of class, and rarely exchanged Tibetan culture with students. They were expected that Han teachers abandoned the inherent viewpoint that Tibetan students were stupid, didn't discriminate against them, and communicate more with them. In fact, here understanding and communication meant not only getting a good understanding of their learning and life, but also getting into their culture world. Only in this way could the inherent prejudices to Tibetan students be abandoned, Tibetan culture and individuals be treated equally.

In the interview, when the teachers were asked, "Do you often communicate with Han/Tibetan teachers? Are there the mutual cultural understandings and dialogues between Han and Tibetan teachers?” The majority of teachers believed that there were some mutual exchanges between Han and Tibetan teachers, but which mainly existed in a small group with better relationship. There existed more exchanges inside this ethnic group, and it was sometimes difficult to integrate into other ethnic group owing to language barriers and the differences in other cultural practices.

\subsection{Absence of Cultural Education in Teacher Education}

Teacher education, including pre-professional training, induction training and job re-education training, isn't a simple, one-time training activity, but a lifelong education process of sustainable development. In the interview, the author learned that in these three stages of teacher education, it was lack of the relevant introduction and education for culture. Especially for “to Support Tibet” teachers, they didn’t receive the relevant cultural educa- 
tion, so that they held their inherent cultural bias into Tibet with rich cultural connotations. They did not have the chance to integrate into the local culture, and did not complete their culture acculturation to Tibetan culture.

During the interview, it's learned that some cultural characteristics were embodied in the school courses. For example, there would be some articles related to the local traditional culture in the subject of Tibetan language. School-based teaching textbook would introduce Tibetan history. In the participation observation, it's found that the students didn't like English and computer classes, but loved the courses like Thangka painting and Tibetan decoration. In teaching Tibetan teachers would attempt to teach something by the use of local traditional culture, while the Han teachers couldn't apply the local culture freely owing to poor understanding of Tibetan culture. It's also difficult for Tibetan teachers to absorb and introduce Han culture mission because of knowing little about Han culture.

\section{Discussion}

Cultural conflicts means the competition and confrontation state generated in the contact process of different cultures. This state comes from each culture often regarding themselves as superior among different ethnic groups. Benedict pointed out, "the style of overweening cultural identity can be found from all parts of the world and all levels of cultural complexity [2].” Therefore, when one culture contacts with another culture in the dissemination process, the conflicts between them will happen. The reasons for the cultural conflicts between teachers and students in Dazi Junior School are as follows.

\subsection{Fewer Number of Tibetan Normal University Graduates, Irrational Faculty Structure}

From the current teacher ratios and educational situation in Tibet, the number of Tibetan normal university graduates in 2013 was 1880, including 1114 undergraduates, 493 college graduates, 273 graduates of infant education [11], in which there were some Han graduates who lived and studied in Tibet. The author compared this figure with the number of schools in Tibet. According to the principle of the average allocation, the ratio of the former to the latter was only 1.69:1, which indicated that in 2013 every school got fewer than two Tibetan normal university graduates. As can be seen from the above data, the lower level of the Tibetan teacher education has resulted in low-quality Tibetan teachers and irrational structure of teachers, which required assistance from outside. The number of minority teachers in Tibetan junior high schools was still low, which accounted for only half of the total number of secondary school teachers. It couldn't suit to the future education development needs of the Tibetan secondary schools in the ethnic enclave with more than $90 \%$ Tibetan people. It's imperative to strengthen Tibetan teacher education construction and speed up the training of highly qualified teachers.

\subsection{Language Becoming a Bottleneck of Teacher Education}

Language as an important carrier of national culture is an indispensable tool for cultural dialogue and heritage. Tibet has taken the measure of "bilingual education" for more than ten years [12], Bilingual teaching is that according to the specific circumstances of learners, the learners are taught the same content from different aspects by a language assisting another language or adopting two different languages, in order to achieve the purpose of learning a certain kind of knowledge and skills. This approach enables Tibetan students study science and technology, inherit the national language, literature and traditional culture, and learn the excellent traditional culture of other nationalities, all of which can effectively promote the modernization of the Tibetan people. However, the poor bilingual teaching ability of Han and Tibetan teachers in Tibet has become the barrier of learning knowledge and culture for students, which makes the language problem become a bottleneck in Tibet's teacher education. The solution of promoting bilingual teaching level is to strengthen teacher training in the teacher education system.

\subsection{Rejection of Self-National Culture to Other Cultures}

Due to different regions and educational evolution, there are significant differences between the various Chinese ethnic cultures. Due to the different cultural characteristics between the inherent culture and the shift-in culture, the former will generate a "rejection" reaction to the latter. Among them, the main feature is culture conflict between the "strong" culture and the "weak" culture, and more severe and powerful shock is the conflict between cultural ideology [13]. The collision of two or more cultures stems from the needs of human beings, while the 
needs are dominated by political and economic factors implicitly behind the cultural exchange.

Teachers' beliefs about multicultural education are rooted in personal life experience in the past, and are formed through interaction with others and the surrounding environment. These beliefs rooted in culture may not help teachers make a teaching plan conforming to physical and mental development of students, and may even have a negative impact on the interaction between teachers and young people. Especially the Han and Tibetan teachers in different ethnic cultural systems are accustomed to regard own and other cultures in a view of ethnocentric with emic approach, which naturally form the view of own culture as the center and the bias and exclusion to other cultures. However, psychological development path of people from birth to mature in different societies, different cultural backgrounds or races have similar or common points, so different ethnic cultures can be largely mutual communication and transformation. Dialectical unity of localization and integration of national education in Tibet is the best interpretation to sustainable development of Tibetan ethnic education under the cultural concept of harmony in diversity.

\subsection{Absence of Multicultural Awareness and Its Education under Certain Circumstances}

The purpose of education is to realize the East-Balance. In Tibetan multicultural system, it's necessary to weaken the instrumental rationality of teacher education, to enhance cultural criticism vision, to pay more attention to the role of multicultural educational environment and to build a multicultural-oriented teacher education model. Professor Jinzhou Zheng believed that "multicultural education starts with cultural diversity in education, so as to enable students with different cultural characteristics enjoy equal educational opportunities. This education is implemented under the condition of respecting different cultures. The aim is to help students develop proper way to treat their own culture and other cultures and the ability to participate in multi culture [8]". Therefore, it requires the teacher education in Tibet to change concepts, respecting other cultures under the self-identity concept to the national culture.

In summary, the present situation of cultural conflicts in Tibetan education has posed constraints on the economic and social further development in Tibet. The fundamental solution lies in further exploring the patterns of teacher education and establishing multicultural teacher education system.

\section{Suggestions}

National development requires educational development first. Educational development requires teacher education development first. Teachers are "professionals" as well as "cultural workers", also teacher cultural buildings and works. From the cultural perspective, the mission of teacher education is to preserve and establish the ecology of the cultural development of teachers to promote teacher's self-development in the cultural ecology. Teacher education system based on multi culture in ethnic minority regions should be established to realize multicultural harmonious symbiosis.

\subsection{Persisting in the Teacher Training Model of Internal Training as the Main Channel and External Assistance, Increasing Cultural Elements in the Curriculum Provision}

Currently, several universities in Tibet shoulder the task of national teacher training. Teacher education must take full account of Tibetan ethnic characteristics and develop a new characterized system of teacher education.

The relevant functional departments of the Tibet Autonomous Region should formulate a scientific and rigorous teacher training programs to strengthen their own "hematopoietic function". Meanwhile inland talents should be actively attracted here to improve the structure and the quality of teachers. By tapping local resources and training more minority secondary school teachers, the configuration mode of teachers is reformed to enhance the stability of teachers and optimize teacher configuration.

For their specific cultural environment, the curriculum provision of teacher education should add more elements of psychology and culturology such as livestock culture, snow area culture and religious culture, and also increase the content of other outstanding Chinese national culture, so as to lay a solid foundation for the process of educational modernization in Tibet.

\subsection{Improving Entry and Appointment Systems, Increasing the Test Content about Ethnic Culture}

In the teacher qualification exam, it's necessary to increase the test content about Han and Tibetan ethnic culture, 
including the assessment of bilingual teaching ability, to urge the candidates to take ethnic culture seriously. It will avoid too many cultural conflicts between teachers and students in the future teaching work which will have an important impact on the teaching effect.

The tenure of teacher qualification age should be broken to reassess teachers' knowledge, skills, cultural quality and other aspects through teacher training, self-learning and other ways every five or ten years. At the cultural level, teachers are required to complete the mission of teaching and carrying forward the ethnic culture.

In teaching, if the strong cultural conflicts between teachers and students owing to the teacher's lack of multicultural consciousness and ethnic discrimination against students have influenced teaching work, it should consider delaying the re-appointment of the teacher seriously. The opinion and measures concerning the entry and appointment system should be implemented one by one.

\subsection{Strengthening Han and Tibetan Teacher Training to Further Improve Their Multicultural Quality}

Teacher training institutions should change their ideas, strengthen the management and attach importance to cultural elements. In the multicultural environment in Tibet, it's necessary to pay much attention to the importance of cultural elements, and cultivate multicultural quality of Han and Tibetan teachers.

In-service teacher training model should be diversified. Effective teacher professional development activities should be school-based and personalized. It's necessary to highlight the importance of school-based training models and trained teachers' subjectivity, strengthen exchanges and assistance between Han and Tibetan teachers, so as to strengthen exchanges and fusion between the Han and Tibetan culture.

Trained teachers should change the inherent cultural values and strengthen their cultural quality. They should abandon the inherent prejudices to other cultures and form the equal cultural values. They should receive and absorb the fine traditional culture by actively participating in job training and actively involving in various forms of cultural dialogue and exchange activities with other teachers and students, to form a common development pattern of mutual respect, mutual learning and mutual supplement.

\subsection{Building Flexible Bilingual Teaching Model to Better Achieve National Cultural Heritage}

Language has a dual nature. On the one hand, language is the carrier of a nation's traditional culture and a symbol of national culture with cohesion of the nation's deep feelings. On the other hand, it's regarded as a tool for information exchange and learning knowledge. Qualified bilingual teachers must be proficient in two languages. On account of the situation of low Han and Tibetan bilingual teaching capability, it's necessary to improve the training institution-building, to establish a unified and coordinated leadership structure, to form bilingual teacher training network with the up and down combination, and the internal and external integration, so as to enhance bilingual teaching capability and create a certain amount of qualified bilingual education teachers.

\subsection{Integrating Teacher's Self-Being and Self-Making Culture, Forming Teacher's Multi-Cultural Ecological Field}

In the real life, teachers are exposed to two lifestyles of self-being and self-making culture. In the self-being culture, the teacher lives in the prospects of experience knowledge and customs, following its current practice and free order. In the self-making culture, teachers lives in the prospects of concepts, theories and systems, pursuing innovation, constantly seeking and self order. Development of teachers needs to integrate the two worlds of life, so that the two cultures continue the process towards one kind of harmony in an interactive, alternate and complementary state [14]. Therefore, a variety of ways should be taken to help pre-service and in-service teachers understand students' cultural backgrounds. Opportunities for cross-cultural experience should be provided teachers to understand students' lifestyle, customs, language, so as to make fusion symbiosis of their own culture and other cultures.

\section{Conclusion}

Culture is a dynamic process. It could promote the nation and the whole people of a country into the modern ranks by carrying forward the national culture, improving the cultural quality of the whole nation, and integrat- 
ing with the whole national culture. In culture-oriented teacher education in Tibet, it's necessary to adhere to the construction of a harmonious multi-cultural ecology in the pursuit of cultural harmony process, to establish the value orientation of harmony in diversity, to uphold cultural attitudes of social commitment and to absorb anything and everything, so as to realize multi-cultural harmonious symbiosis.

\section{References}

[1] Yi, J.Q. (2004) Fifteen Lectures of Cultural Philosophy. Peking University Press, Beijing.

[2] Benedict, R. (2009) Patterns of Culture. Social Sciences Academic Press, Beijing.

[3] George, F.K. (1978) Educational Anthropology: An Introduction. R. E. Krieger Publishing Company.

[4] Ding, G. (2009) Transmission and Evolution of Culture. Guangxi Normal University Press, Guilin.

[5] Yang, J. and Peng, G.C. (2004) Culture Conflict and beyond on Cultivating the Humanistic Spirit in Chinese Education. Journal of Southwest University for Nationalities (Humanities and Social Science Edition), 11, 27-31.

[6] Chen, Z.Z. (2000) Reviewing the Conflict between Teachers and Students-A Kind of Sociological Analysis. Education Review, 2, 32-35.

[7] Jin, Y.L. (2003) The Basic Train of Thought of Basic Education Curriculum Reform in the Multicultural Background. Journal of Education Research, 12, 5-8.

[8] Zheng, J.Z. (2004) Multicultural Education. Tianjin Education Press, Tianjin.

[9] Wan, M.G. (2006) The Comparative Research on Multicultural Education. National Publishing House, Beijing.

[10] Hu, W.Z. (1999) Introduction to Intercultural Communication. Foreign Language Teaching and Research Press, Beijing.

[11] Bureau of Tibet Autonomous Region (2013) Tibet Statistical Yearbook. China Statistics Press, Beijing.

[12] Ma, R. (2011) Social Development and Bilingual Education in Tibet. Chinese Tibetology, 2, 108-139.

[13] Zhuang, X.D. (2003) Cultural Transmission: History, Theory and Reality. People Publishing House, Beijing.

[14] Long, B.X. (2009) Research on Cultural Innovation of Teacher Education. Education Science Press, Beijing. 